\title{
História e identidade angolana em Luandino Vieira: quem é o nosso de Nosso musseque?
}

Gustavo Henrique Rückert ${ }^{1}$

\begin{abstract}
This paper has as its main objective to analyze the relationship between the work Nosso musseque, by José Luandino Vieira, and the Angola's history writing and construction of identity. The theoretical underpinnings of post-colonialism sustain the role of African literature in understanding and reconstruction the history and search for a sense of national identity. Hence, this study begins in formal aspects of this novel, as the genre, the narration and, finally, the diegesis, to reflect on the meanings that these elements take on this perspective.
\end{abstract}

Key-words: Luandino Vieira; Nosso musseque; history; identity.

Resumo: O presente trabalho tem como principal objetivo analisar as relações da obra Nosso musseque, de José Luandino Vieira, com a escrita da história e com a construção de uma identidade angolana. A partir de fundamentos teóricos do Pós-colonialismo, assume-se a função das literaturas africanas no entendimento e na reconstrução da história, bem como na busca por uma noção de identidade nacional. Dessa forma, o estudo parte de aspectos formais desse romance, como o próprio gênero, a narração e, por fim, a diegese, para refletir sobre os significados que esses elementos assumem nessa perspectiva.

Palavras-chave: Luandino Vieira; Nosso musseque; história; identidade.

A luta contra a opressão colonial não apenas muda a direção da história ocidental, mas também contesta sua ideia historicista de tempo como um todo progressivo e ordenado.

Homi K. Bhabha, "O local da cultura"

A relação dos países africanos recém emergentes do sistema colonial com a história é bastante distinta daquela dos países dito ocidentais. Se a história moderna é a história da colonização, é a partir de uma tradução de diferentes signos que se constrói a própria

1 Doutorando em Literaturas Portuguesa e Luso-Africanas pelo Programa de Pós-graduação em Letras da UFRGS. 


\section{Conexão Letras}

história de Angola e dos demais países que foram submetidos aos domínios imperiais de Portugal e das outras nações europeias.

Vinculado à história da colonização está o processo de constituição identitária nacional. De acordo com o africanista Patrick Chabal (1998), a identidade nacional é um fenômeno eurocêntrico que se desenvolve, principalmente, no século XVI. Não à toa, é um século de viagens, conquistas e descobertas do outro. Esse outro foi fundamental para a formação do constructo identitário europeu por sustentar o pólo negativo de uma identidade baseada em oposições binárias. $\mathrm{O}$ africano (ou o americano) era o bruto, o selvagem, o sem fé, nem lei, nem rei. A identidade do colonizador fez-se pela não-identidade do colonizado. Justificava-se assim todo o sistema de exploração através de uma missão civilizatória.

Dessa forma, não é difícil de perceber que a história das recentes nações africanas é a história da negação. A positivista história moderna europeia, com sua narrativa linear e diacrônica, sustentada pelos grandes marcos e documentos oficiais, e com as pretensas objetividade e neutralidade científica de um observador, claramente, não deu conta da complexidade da relação do africano com a dominação colonial. As narrativas totalitárias e baseadas nos essencialismos filosóficos que sustentaram, durante muito tempo, o conceito de verdade foram, justamente, alguns dos instrumentos do sistema colonial. Esses instrumentos culturais (religião, língua, história) constituíram a via da violência implícita ( Tutikian, 2006: 93), que acabou por sufocar a cultura dos povos africanos.

A identidade está estreitamente relacionada com a narrativa histórica. De acordo com Stuart Hall (2006: 51), ela gera sentidos ao conectar o passado com o presente de uma nação. E a história africana é composta de mutilações. Para citar alguns desses cortes, de ordem extremamente complexa, referimo-nos à Conferência de Berlim, realizada de 1884 a 1885, inclusive sob forte pressão portuguesa. Esse encontro teve como pauta a retaliação do território africano. A noção europeia de limites geopolíticos, bem como de propriedade privada da terra, foi imposta com cortes retilíneos sobre a terra de África, separando tribos e ocasionando uma mudança forçada e irreparável na organização social dos povos africanos. Aliamos a esse episódio os forçados movimentos diaspóricos que tiveram como força motriz o tráfico de escravos, que também ocasionaram mudanças irreparáveis nas sociedades africanas. Esses são apenas alguns dos signos a serem traduzidos e organizados na complexidade da construção histórica e identitária dos países africanos.

Sendo assim, não é difícil de entender que a literatura tenha tomado papel importantíssimo nessa difícil empreitada, sobretudo em Angola. A revisão da história colonial europeia, bem como a construção da história e da identidade angolana, tornam-se motes para a literatura, como é o destacado caso de Luandino Vieira. A história única e as identidades essencialistas, portanto, acabam dando lugar à noção do híbrido, do deslizante e do fragmentado. Os grandes marcos históricos são subvertidos pelas narrativas do cotidiano, dos ditados populares, da ficção. Reinterpretar o passado, durante as décadas de 60 e 70, tornou-se condição sine qua non para entender os conturbados tempos do presente, marcados pela consciência nacional, pela guerrilha, pela repressão portuguesa e pela independência.

Nesse sentido, refletimos a questão da história e da identidade em Nosso musseque, livro escrito pelo angolano (porque assim o quis) Luandino Vieira, nos pavilhões prisionais da PIDE (assim como tantos outros na sua obra), durante a década de 60. Apesar de publicado somente em 2003, pela Editorial Caminho, esse romance atende às necessidades de seu contexto de produção: durante esses anos de forte conscientização e pressão pela independência de Angola (que viria a concretizar-se na década seguinte), e também de forte ação repressora do governo fascista de Salazar, era necessário entender a origem desse 
despertar de consciência, revisitando a história dos anos 40 (aproximadamente o espaço temporal da diegese da obra).

Para analisar as questões histórico-identitárias presentes em Nosso musseque, partimos de uma divisão estrutural entre nível narrativo e nível diegético, sabendo, entretanto, que estes não funcionam de modo isolado, mas, sim, estão interligados no processo de significação. Toda classificação é, no fim das contas, meramente analítica. Sendo assim, sabendo que a divisão não corresponde a uma verdade ontológica, partimos dela por questões organizacionais e de metodologia, a fim de tornar mais claro o estudo, porém com a pretensão de atar os níveis ao fim da reflexão proposta.

\section{Nível narrativo}

De acordo com Ana Mafalda Leite,

As literaturas africanas emergentes (...) recorrem aos seus próprios espaços culturais, periféricos do ponto de vista do centro, em busca não de uma mítica ou pretensa "autenticidade" pré-colonial, mas do material poético nativo, passado e presente (...) que lhes garanta a "invenção" de um campo literário diferente, sujeito à recuperação, integração e eventual hibridação também de modelos outros, estrangeiros. (LEITE, 2003: 27-28)

Assim, com a subversão e a hibridação dos modelos narrativos ocidentais pela presença da tradição narrativa (oral) africana, as literaturas das ex-colônias em África inovam e enriquecem a(s) tradição(ões) literária(s). Nosso musseque é catalogado como romance e utiliza de características euro-ocidentais desse gênero. No entanto, a obra também subverte essas características genológicas. Ian Watt, em A ascensão do romance (1990), explica que esse gênero é a expressão artística da burguesia, e, não por acaso, é durante o mesmo período da ascensão dessa classe que ele se consolida como gênero. As grandes narrativas dos séculos XVIII e XIX, portanto, acabaram por concretizar esse gênero, uma vez que surgia um novo público leitor e, com ele, uma nova necessidade de representação e expressão na simbologia cultural. Os tradicionais romances (Sthendal, Balzac, Flaubert, Dickens, Tolstoi, Eça, só para ficar em alguns exemplos) possuíam a pretensão realista de ser uma cópia fiel da realidade do indivíduo, recriando todo um universo complexo da sociedade que o cerca, do espaço e do tempo, de modo homogêneo e total, por meio de uma narrativa construída por um narrador, normalmente, onipresente - que poderíamos dizer totalitário.

Ao contrário das certezas e verdades presentes nos discursos narrativos que caracterizaram o romance, e da pretensa reprodução de uma totalidade por meio dessa narração, notamos, em Luandino Vieira (assim como em muitos autores contemporâneos), uma narrativa consciente de que toda narração é, no fim das contas, constituída por recortes e por escolhas e, justamente por isso, será sempre parcial. O narrador de Nosso musseque, em primeira pessoa, conduz o foco narrativo para diferentes personagens com suas diferentes impressões e pontos de vista (a obra é dividida em espécie de estórias - ao estilo popular do missosso ${ }^{2}$ angolano: Zeca Bunéu e outros; A verdade acerca do Zito; Carmindinha e $e u)$. Essas estórias vão sendo narradas a partir da pesquisa desse narrador acerca de sua

2 Conto, estória. 


\section{Conexão Letras}

infância no musseque ${ }^{3}$. Dessa forma, a fragmentação resultante dos lapsos de memória, da falta de uma ordem cronológica linear, da consulta de fontes e, ainda, da pluralidade do foco narrativo que recai sobre alguns personagens, confere à narrativa uma noção lacunar e de incompletude.

As fontes dessa pesquisa são das mais variadas: vão desde as próprias lembranças dos fatos que o narrador testemunhou até os jornais antigos organizados pela turma do musseque ou escritos pelo capitão Bento; desde os relatos das senhoras e dos meninos até os fragmentos do caderno de Xoxombo, salvos do fogo por Zeca - que sempre ouvia e contava histórias e, por isso, constitui-se como importante fonte para a construção da narrativa. Dilui-se, assim, a questão da verdade (tão cara ao mundo ocidental), pois o que mais importa na narrativa são as estórias em si e a competência na narração dos casos. Logo no início da obra, isso já é perceptível, quando o narrador prepara-se para contar a história de Xoxombo:

Talvez agora com as coisas que os anos e a vida mostraram, vindas de muitas pessoas diferentes, eu possa pôr bem a história do Xoxombo. Se não conseguir, a culpa não é dele nem da confusão que lhe pôs a alcunha. É minha, que meti literatura aí onde tinha vida e substituí calor humano por anedota. Mas vou contar na mesma. (2003: 17)

Fica claro, portanto, que houve uma preparação desse narrador, com o amadurecimento e o distanciamento dos fatos narrados. Houve também a consulta a pessoas diferentes. As múltiplas visões sobre o episódio da morte do menino Xoxombo, ferido por um bode, vão desde a versão do também menino Zeca, de que o amigo teria abusado de uma cabra, até a negação dessa versão pela família de Xoxombo, que alegava que o menino - pequeno e ingênuo - tentou proteger a cabra com o próprio corpo das investidas do bode. A contradição das versões, assim como a inexistência de qualquer elemento que comprove a veridicidade de qualquer uma delas, não é problema para o discurso do narrador. Ao contrário disso, é na pluralidade e na possibilidade que reside a riqueza dessa narração, subvertendo e enriquecendo o próprio gênero romanesco ao unir ao gênero europeu a relação do africano com a(s) história(s). A personagem Zeca - uma das principais fontes do narrador -, que gosta de contar histórias ao seu modo, é bastante significativa nesse sentido: "Não é bem como ele fala, que sucedeu: o Zeca, cadavez que conta, mete sempre as partes dele e, quando a gente vai ver, ninguém sabe mais onde está a verdade e onde está a mentira." (2003, 31).

Dessa forma, a narrativa da obra em questão (e isso é tão significante quanto a própria diegese) não se propõe ao fechamento, ao autoritarismo de um único ponto de vista dado como verdade e à imposição de significados ao leitor. Pelo contrário, o romance de Luadino Vieira é híbrido desde o aspecto genológico, e isso muito devido ao seu foco narrativo, mostrando diversos pontos de vista dos mesmos fatos, incorporando estórias contadas, ouvidas e recontadas, anotações em um caderno, recortes de jornal e que vão montando uma narrativa sem pudores da sua condição incoerente e contraditória. É importante ressaltar, porém, que essa não é uma síntese harmoniosa. De acordo com Stuart Hall (2008: 71), “[o hibridismo] trata-se de um processo de tradução cultural, agonístico uma vez que nunca se completa, mas que permanece em sua indecibilidade”. Os próprios processos de constituição da identidade (que são narrativos), sobretudo das identidades nacionais africanas, já nasceram tendo a consciência da ilusão essencialista nesse aspecto.

3 Denominação para os bairros populares de Angola. 
A identidade, que é uma construção discursiva, entrecruza-se com outros discursos, caso claro da história, e faz-se, portanto, pela não imposição, pela não verdade e não totalidade acerca de uma narrativa da história e da identidade angolana.

\section{Nível diegético}

Uma vez que a diegese de Nosso musseque é composta pelas várias estórias que vão sendo recordadas no nível narrativo, uma análise que pretenda dar conta de todas as situações ficcionalizadas é, desde o início, fadada ao insucesso pela falta da devida atenção aos pequenos casos narrados. Cada uma dessas cenas possui a mesma importância para a interpretação da obra, parecendo não se subjugarem em uma ordem hierárquica de acontecimentos. Partiremos, portanto, de alguns episódios específicos para a análise proposta neste capítulo.

O primeiro momento aqui selecionado é durante a chegada da família do português Sô Luís no musseque. Ele, que é uma autoridade policial, já nos primeiros dias, fechou para si um quintal de árvores frutíferas que era aberto. Sempre que havia necessidade, a comunidade do musseque retirava de lá alguns alimentos. O espaço ainda era de suma importância para as crianças, que por lá brincavam livremente. Essa noção da terra como um bem comum foi violada pelo branco que privatizou para si a área. A reação dos moradores acabou vindo com ofensas étnicas. "Ngueta camuelo4. Esses brancos são assim. Olha só! Chegou dois dias e pronto! Começa já a dizer aquilo é dele.” (2003: 37)

Outro episódio semelhante ocorre quando algumas famílias do musseque foram desapropriadas de suas cubatas 5 , já que, com o crescimento de Luanda, os donos das habitações almejavam outras aplicações para esses terrenos. Ainda antes do despejo das famílias, quando não havia dinheiro para o pagamento do aluguel, o cobrador simplesmente adentrava as moradias e tomava alguns pertences de valor. A reação a essas explorações sofridas leva os moradores do musseque a algumas atitudes de resistência, como a agressão das mulheres a um tratorista que derrubava as cubatas e do menino Zito ao cobrador Aníbal. A consciência identitária começa a levantar-se pelo binarismo, uma vez que os antigos moradores do musseque enxergavam-se explorados por aqueles que exerciam o poder. A reação étnica faz-se presente e as palavras pejorativas para a designação principalmente de brancos (cangundo, Ngueta, Ngueta camuelo, Ngueta da tuji), mas também de alguns mulatos (sungaribengo), são comuns no discurso das personagens.

Cabe lembrar, no entanto, que estamos falando de recordações da infância no musseque. Por mais que a repressão por parte dos portugueses mostrasse a essas crianças que a resistência dos africanos seria uma idealização e teria, por consequência, mais repressão, elas pareciam ainda não se aperceber disso. Nanito, filho do policial Luís, puniu Zeca com um tiro no traseiro. E essa atitude nada mais era que um reflexo das atitudes do pai: juntamente com Aníbal, ele queria promover uma "limpeza" (e o termo empregado pela personagem era mesmo este) no musseque. As crianças, contudo, ainda não entendiam a gravidade dos significados desses acontecimentos. Exemplo claro disso é Xoxombo, que achava a sua professora uma moça muito boa porque o defendia das chacotas étnicas dos brancos. O discurso dela, porém, reproduzia os mesmos preconceitos:

A sô pessora é boa mas eu não gosto dela. Quando os meninos começam-me fazer pouco chamando-me Xoxombo-macaco e outras coisas, ela aparece sempre (...).

4 Branco ordinário e avarento.

5 As casas típicas dos musseques. 
Diz eu sou coitadinho não tenho culpa de ser assim escuro e que a minha alma é igual (...) (2003: 47).

Essa geração foi crescendo em meio a um ambiente caótico e em pulsante tensão de conflito. Aos poucos, os meninos foram perdendo a segurança das suas fantasias infantis e começaram a entender o contexto ao seu redor. Talvez o momento mais significativo dessa passagem de consciência seja o episódio do natal. O narrador, amparado em escritos do caderno de Xoxombo, conta que eram distribuídos presentes para as crianças nessa data. Zeca e Xoxombo sonhavam com caminhonetes de corda. Na distribuição de presentes, em meio ao desespero de tantas crianças com fome de sonho frente ao paraíso da mesa de brinquedos, os dois se perderam. Zeca, que tinha fama de malandro, conseguiu convencer a jovem professora (a mesma de Xoxombo) a dar-lhe uma caminhonete. Quando ela já estava com a mão no brinquedo, um professor magro, reclamando da demora do serviço, pegou um apito, deu a Zeca, e mandou-o embora. "Pronto! Vai-te embora. Vêm para aqui esses miúdos vadios...musseque, musseque!” (2003: 59), dizia ele.

Desolado, com as lágrimas a correr, Zeca esperava pelo amigo Xoxombo. Este retornou também chorando e com o rosto ferido. "A sô pessora me deu-me um xatete de corda que eu lhe pedi. Depois, na confusão, um senhor me tirou a xatete e deu num miúdo branco que estava a pedir!" (2003: 60). Ele ainda tentou brigar com a criança branca mas a professora separou e deu-lhe uma língua-de-gato. Nesse dia, além dos brinquedos sonhados esses meninos perderam um pouco da inocência. Isto é simbolizado na volta ao musseque, quando os dois decidiram jogar fora as suas caminhonetes de papelão, desfazendo-se, assim, da infância. A anotação de Xoxombo no seu caderno, contudo, revela uma inquietação ainda maior, que levaria os meninos a perda de mais brinquedos, infâncias ou inocências:

Eu e o Zeca fomos nos brinquedos. Nos meninos brancos deram caminhonetas de corda e a mim não porque sou muito preto. Mas no Zeca também não deram e ele é branco. O filho do sô Laureano da Câmara recebeu. Não percebo. (2003: 62).

Com a superação da bipolaridade étnica parecia florescer a consciência de uma nação de identidade híbrida em meio à repressão, que só crescia. E um dos momentos fundamentais para isso é o amadurecimento de Carmindinha. "Os soldados (...) vinham bater nas portas e janelas chamando todas as mulheres e meninas de putas, tinham cuspido na cara dos velhos, invadindo mesmo as cubatas" (2003:172). A exploração da gente dos musseques era tanta que deu origem a uma revolta. "A raiva correu calada até na ponta dos dedos que procuravam velhas facas e catanas" (2003:170). Dessa forma, em um domingo, os moradores revoltados partiram para cima dos soldados. Acuados, estes se refugiaram em uma igreja em plena missa. No entanto, a fúria dos explorados dos musseques parecia ter sido provocada para uma cilada que levaria a desejada "limpeza", pois logo chegaram outros soldados e cercaram os angolanos, promovendo uma chacina que não poupou nem os velhos, as mulheres e as crianças.

Carmindinha presenciou esse fato, pois estava na missa com a mãe, e passou, desde então, a questionar o seu pai. E isso é simbolicamente muito forte, uma vez que a sabedoria dos mais velhos é inquestionável na cultura africana. Acusava ela: "Batem-te na tua porta, insultam-te na tua filha e você fica com seu respeito, sua educação, não liga nessas coisas, não é? Fala que o povo só quer é vinho e roubo, mulheres, vestir casaco e gravata, que já não tem homens como antigamente..." (2003:176). Em resposta a essa imobilidade do pai, a inconformada Carmindinha não aceita as acusações de aculturação dos angolanos pelos 
portugueses feita pelo pai e rebate: "Isso tudo já morreu, Senhor Capitão! Está morto, não serve para nada papá!... Agora não é hora de esperar que o Zeca vai-se instruir, que eu vou m’instruir, todos são educados e vamos fundar nossa associação literária!"' (2003:179).

Quem acaba morrendo na obra é o próprio Senhor Capitão. O mestre, experiente por anos de navegação, sábio pelo estudo e ativo na escrita em jornais, representava a busca pela tradição. Com ele, morrem os essencialismos. Acabam ficando, porém, ensinamentos que serão importantes. Junto com a revolta de Carmindinha, amadurece a consciência de uma identidade híbrida, a partir dessas vozes exploradas que, negras mas também brancas e mestiças, foram sempre condenadas à não-identidade. Identidade essa que passa a compreender a tradição mas não buscar reproduzi-la, já que os tempos são outros e as demandas também. Prova dessa compreensão é que o olhar do Capitão sobrevive no olhar de Carmindinha. "Dizia o Zeca Bunéu que, sem esse olhar, Carmindinha não existia (2003:186) ".

\section{Considerações finais}

A escolha da associação literária por Carmindinha como uma forma de resistência à colonização não é uma representação aleatória. Justamente a expressão literária foi tão importante na construção de uma identidade angolana e, posteriormente, na independência do país. $\mathrm{E}$ para a construção dessa identidade, a revisão da história foi fundamental. Era necessária não uma História Oficial, positivista, com progressão temporal e lógica que marginaliza e nega a identidade ao angolano, mas a história dos musseques, a história multifocal, a história não linear, a história das recordações de fatos cotidianos tendo como fonte relatos, conversas, jornais e cadernos que constitui um romance que, como disse Ana Mafalda Leite, reinventa o gênero literário de base europeia ao enriquecer o seu texto com as tradições africanas. A maior expressão da história de Angola não está em livros científicos aos moldes ocidentais, mas sim na expressão literária de nomes como Luandino Vieira e Pepetela. Em Nosso musseque, portanto, há uma das mais ricas representações (e, ao mesmo tempo, recriação) do despertar, durante a década de 40, para uma identidade consciente do seu próprio processo de construção e da impossibilidade de sua essencialidade.

O contexto grávido de conflitos dos anos 40 acabou por desaguar, na década de 50, na reunião de intelectuais angolanos em prol da identidade e da luta pela libertação nacional, na criação dos primeiros partidos políticos, editoras, cinemas e teatros. Já no início dos anos 60, uma vez que a repressão portuguesa tornara-se ainda mais violenta, tem-se início o movimento da luta armada com o MPLA. Desse modo, é o despertar de consciência dos meninos do musseque, com seus jornais e associações literárias, que dá início a compreensão do passado histórico e, assim, a luta pela escrita do presente e do futuro de Angola.

\section{Referências}

BHABHA, Homi K. O local da cultura. Trad. Myriam Ávila, Eliana Lourenço de Lima Reis e Gláucia Renate Gonçalves. Belo Horizonte, Editora UFMG, 1998.

BURKE, Peter (org). New perspectives on historical writing. Pennsylvania, The Pennsylvania State University Press, 1995.

CHABAL, Patrick. What is Africa? Interpretations of post-colonialism and identity. In: ROSA, Victor Pereira da e CASTILlO, Susan (org.) Pós-colonialismo e Identidade. Porto, Edições da Universidade Fernando Pessoa, 1998. 


\section{Conexão Letras}

FERREIRA, Manuel. Literaturas africanas de expressão portuguesa. Lisboa, Instituto de cultura portuguesa, 1977.

HALL, Stuart. Da diáspora: identidades e mediações culturais. Trad. Adelaine La Guardia Resende et alii. Belo Horizonte, Editora UFMG, 2008.

identidade cultural na pós-modernidade. Trad. Tomaz Tadeu da Silva e Guacira Lopes Louro. Rio de Janeiro, DP\&A, 2006.

HUTCHEON, Linda. Descentralizando o pós-moderno: o ex-cêntrico. In: Poética

do pós-modernismo: história, teoria, ficção. Trad. Ricardo Cruz. Rio de Janeiro, Imago, 1991. 84-103.

LEITE, Ana Mafalda. Literaturas africanas e formulações pós-coloniais. Lisboa, Colibri, 2003.

TUTIKIAN, Jane. Velhas identidades novas: o pós-colonialismo e a emergência das nações de língua portuguesa. Porto Alegre, Sagra Luzzatto, 2006.

VIEIRA, José Luandino. Nosso musseque. Lisboa, Editorial Caminho, 2003. 